\title{
Níveis de energia em suplementos múltiplos para terminação de novilhos em pastagem de capim-braquiária no período de transição águas-seca ${ }^{1}$
}

\section{Maykel Franklin Lima Sales ${ }^{2}$, Mário Fonseca Paulino ${ }^{3}$, Marlos Oliveira Porto ${ }^{2}$, Sebastião de Campos Valadares Filho ${ }^{3}$, Tiago Sabella Acedo $^{4}$, Victor Rezende Moreira Couto ${ }^{4}$}

${ }^{1}$ Apoio da FAPEMIG e do CNPq.

2 Programa de Pós-graduação em Zootecnia - UFV, Viçosa-MG, CEP: 36570-000. Bolsista do CNPq.

${ }^{3}$ Departamento de Zootecnia - UFV, Viçosa-MG, CEP: 36570-000. Pesquisador do CNPq.

${ }^{4}$ Curso de graduação em Zootecnia, DZO-UFV, Viçosa-MG, CEP: 36570-000.

RESUMO - Estudaram-se os efeitos de níveis de energia em suplementos múltiplos sobre o desempenho produtivo e os parâmetros nutricionais de bovinos em fase de terminação mantidos em pastagem de capim-braquiária (B. brizantha cv. Marandu) durante o período de transição águas-seca. Para avaliação do desempenho produtivo, utilizaram-se 24 novilhos mestiços, não-castrados, com 18 meses de idade e peso corporal médio inicial de $330 \mathrm{~kg}$, distribuídos em delineamento inteiramente casualizado, em quatro piquetes de 1,5 ha. Avaliaram-se quatro tratamentos: mistura mineral (MM) e suplementos formulados à base de milho e grão de soja em três níveis de fornecimento (1,0; 1,5 e 2,0 kg/dia) para permitir consumo de NDT de 0,832; 1,163 e 1,496 kg/dia, respectivamente. Houve efeito linear positivo dos níveis de energia sobre o ganho médio diário e o peso vivo final. Os parâmetros nutricionais foram avaliados em quatro novilhos mestiços nãocastrados com peso médio inicial de $300 \mathrm{~kg}$, fistulados no esôfago, rúmen e abomaso, alimentados com dietas semelhantes às dos animais utilizados no experimento de desempenho. Não houve efeito da suplementação sobre o consumo de matéria seca total, mas houve redução linear no consumo de forragem da pastagem (MSP). Os consumos de matéria orgânica proveniente do pasto, de FDN da dieta total e de FDN da pastagem foram afetados linear e negativamente pelos níveis de energia. Não foram encontrados efeitos dos níveis de suplementação sobre a digestibilidade total dos nutrientes, com exceção da PB, que foi influenciada de forma quadrática pelos níveis de suplementação. Ganhos de peso adicionais de 20 a $30 \%$ podem ser obtidos com quantidades crescentes de energia na fase de terminação, contudo, esses ganhos dependem da substituição do consumo de forragem pelo suplemento.

Palavras-chave: digestibilidade ruminal, gado de corte, milho, pastagens, soja, suplementação

\section{Energy levels in multiple supplements for finishing beef cattle grazing palisade grass pasture during the rainy to dry transition season}

\footnotetext{
ABSTRACT - The effects of energy levels in multiple supplements on productive performance and nutritional parameters were evaluated of finishing beef cattle grazing palisade grass (Brachiaria brizantha cv. Marandu), during the rainy to dry transition season. For the performance evaluation, 24 crossbred bulls, 18 month old and $330 \mathrm{~kg}$ of initial body weight (BW), were distributed to a completely randomized design, in four paddocks of 1.5 ha each. Four treatments were evaluated: mineral mix (MM) and corn and whole soybean grain based supplements offered in three levels: 1.0 ; 1.5 and $2.0 \mathrm{~kg} / \mathrm{d}$, allowing TDN intake of, respectively, $0.832 ; 1.163$ and $1.496 \mathrm{~kg} / \mathrm{d}$. There was a positive linear effect of the energy levels on the average daily gain and on the final body weight. The nutritional parameters were assessed in four crossbred bulls, with average initial $300 \mathrm{~kg} \mathrm{BW}$, fitted with esophageal, ruminal and abomasal cannula, and fed similar diets of those animals used in the performance. There was no ffect of supplementation on dry matter intake (DMI) although it was observed a linear reduction in forage intake. The intakes organic matter from pasture, of the NDF from the total diet and of the pasture was negative linearly affected by the energy levels. There were not observed effects of supplementation levels on the total apparent digestibility of the nutrients, except for CP, which showed a quadratic effect by the level of supplementation. Additional weight gain, ranging from 20 to $30 \%$, can be obtained in beef cattle supplemented with increasing amounts of energy during the finishing phase; however, those gains depend of the substitution of forage intake by the supplement.
}

Key Words: beef cattle, corn, pasture, ruminal digestibility, supplementation, soybean 


\section{Introdução}

A digestibilidade e o consumo são dois dos principais componentes que determinam a qualidade de um alimento. De todos os nutrientes necessários às exigências nutricionais para mantença, crescimento e/ou produção dos bovinos, a energia, principalmente na forma de celulose e hemicelulose, constitui a principal contribuição dos volumosos. A extensão da digestão microbiana dos carboidratos no rúmen relaciona-se à digestibilidade do volumoso e, juntamente com a taxa de digestão desses mesmos carboidratos, determina o valor nutritivo para o ruminante, tanto do aspecto energético como do aspecto protéico (Gomide, 1974).

Segundo Mertens (1994), o valor nutritivo de um volumoso pode ser avaliado pela sua digestibilidade e pelos seus teores de proteína bruta e de parede celular, características estreitamente correlacionadas ao consumo de matéria seca (CMS).

Volumosos de baixa qualidade são importantes fontes de nutrientes utilizadas para manter bovinos de corte, principalmente nos países em desenvolvimento. Para otimizar a utilização desses nutrientes e manter o desenvolvimento animal aceitável, geralmente é desejável aumentar a ingestão e digestão pelo fornecimento de nutrientes suplementares (Köster et al., 1996). Segundo Minson (1990), a quantidade de matéria seca ingerida pelo animal constitui-se no principal fator na produção de ruminantes a pasto.

A baixa produção animal na época seca é atribuída, principalmente, ao baixo CMS, ou seja, ao baixo consumo de energia e à deficiência de proteína e minerais nos pastos; nesta época, as pastagens apresentam freqüentemente baixa disponibilidade e proporção de folhas verdes e alta disponibilidade de colmo e material morto, e são pouco consumidas, mesmo que o suprimento de forragem total seja abundante (Minson, 1990; Noller et al., 1997).

Paulino \& Ruas (1988) mencionaram que o aumento da eficiência na produção de bovinos no Brasil está incondicionalmente relacionado à melhoria das condições de alimentação e que a suplementação é uma das alternativas mais práticas para adequar suprimento de nutrientes aos requerimentos dos animais, especialmente durante a seca.

A produção de carne de melhor qualidade, com a terminação de animais jovens, pode resultar em maior rentabilidade da atividade sem, no entanto, aumentar o preço do produto ao consumidor, uma vez que os recursos adicionais investidos nesse sistema de produção podem propiciar a redução do número de categorias animais na propriedade. Como conseqüência tem-se mais espaço para matrizes, resultando em aumento na produção de bezerros e aumento na taxa de desfrute.
Objetivou-se avaliar suplementos formulados com níveis crescentes de energia sobre o desempenho produtivo e parâmetros nutricionais de bovinos na fase de terminação em pastagem de Brachiaria brizantha cv. Marandu no período de transição águas-seca.

\section{Material e Métodos}

Foram utilizados 24 novilhos mestiços não-castrados, com 18 meses de idade e peso médio inicial de $330 \mathrm{~kg}$, distribuídos em quatro piquetes de Brachiaria brizantha cv. Marandu com 1,5 ha cada, providos de bebedouros e cochos cobertos para distribuição do suplemento.

O período experimental foi composto de três períodos de 28 dias e um período de 26 dias, totalizando 110 dias de avaliação. Os animais foram pesados ao início do experimento e a cada 28 dias. $\mathrm{O}$ ganho de peso total foi determinado pela diferença entre o peso final e o inicial, após período de jejum hídrico e alimentar de 18 horas.

Avaliaram-se quatro tratamentos: mistura mineral (MM) e suplementos à base de milho e grão de soja moído em três níveis de fornecimento: 1,0; 1,5 e 2,0 kg/dia. Os suplementos contendo milho e/ou grão de soja foram formulados para permitir consumo de nutrientes digestíveis totais (NDT) de 0,832; 1,163 e 1,496 kg, respectivamente, para os níveis de suplementação 1,0; 1,5 e 2,0 kg/dia (Tabela 1). O consumo de PB via suplemento foi de $0,300 \mathrm{~kg} /$ dia. Todos os animais avaliados receberam diariamente $60 \mathrm{~g}$ de $\mathrm{MM} / \mathrm{dia}$.

Os suplementos foram fornecidos diariamente, às $10 \mathrm{~h}$. Os animais foram rotacionados semanalmente entre os piquetes visando à eliminação de possíveis efeitos de

Tabela 1 - Composição em ingredientes e quantidades diárias de NDT e PB fornecidas pelos suplementos, com base na matéria natural

\begin{tabular}{|c|c|c|c|c|}
\hline \multirow[t]{2}{*}{ Item } & \multicolumn{4}{|c|}{ Suplemento } \\
\hline & $\mathrm{MM}^{\mathrm{a}}$ & $\mathrm{GS} 1,0^{\mathrm{b}}$ & MGS1, $5^{c}$ & $\operatorname{MGS} 2,0^{\mathrm{d}}$ \\
\hline \multicolumn{5}{|l|}{ Ingrediente (\%) } \\
\hline Mistura mineral ${ }^{1}$ & 100,0 & - & - & - \\
\hline Soja moída & - & 100,0 & 57,0 & 36,0 \\
\hline Milho moído & - & - & 43,0 & 64,0 \\
\hline \multicolumn{5}{|c|}{ Quantidade diária (kg) } \\
\hline NDT $(k g)^{2}$ & 0,00 & 0,832 & 1,163 & 1,496 \\
\hline PB (kg) & 0,00 & 0,312 & 0,306 & 0,303 \\
\hline
\end{tabular}

a mistura mineral; b grão de soja moído, $1,0 \mathrm{~kg} / \mathrm{dia} ;{ }^{\mathrm{c}}$ milho + grão de soja moídos, 1,5 kg/dia; d milho + grão de soja moídos, $2,0 \mathrm{~kg} / \mathrm{dia} ;{ }^{1} \mathrm{Composição}$ percentual: cloreto de sódio $(\mathrm{NaCl})$ : 47,15 ; fosfato bicálcico - 50 ; sulfato de zinco-1,5; sulfato de cobre - 0,75; sulfato de cobalto - 0,05 ; iodato de potássio - 0,05; sulfato de magnésio - 0,5. ${ }^{2}$ Estimado segundo o NRC (2001). 
ambiente sobre os tratamentos. No primeiro dia de cada período experimental, foram realizadas as coletas de forragem para determinação da disponibilidade de matéria seca total (DMST), por meio do corte, rente ao solo, de cinco áreas delimitadas por um quadrado metálico de $0,25 \mathrm{~m}^{2}$, selecionadas aleatoriamente em cada piquete experimental.

No momento da coleta, procedeu-se à divisão da amostra em duas partes. Uma das amostras foi pesada e levada imediatamente à estufa com ventilação forçada, a $65^{\circ} \mathrm{C}$ por 72 horas, para determinação da DMST da pastagem. A outra foi separada em folhas verdes, folhas secas, colmos verdes, colmos secos e material morto para determinação dos componentes estruturais da pastagem. A amostragem do pasto consumido pelos animais foi obtida via coleta de extrusa esofágica.

As determinações de MS, MO, NT, extrato etéreo (EE) e lignina foram realizadas segundo técnicas descritas por Silva \& Queiroz (2002). A determinação do nitrogênio insolúvel em detergente neutro (NIDN) e insolúvel em detergente ácido (NIDA) foi obtida conforme descrito por Van Soest et al. (1991). Os teores de FDN e fibra em detergente ácido (FDA) foram determinados conforme metodologia descrita por Pell \& Schofield (1993), denominada método do autoclave. A correção da FDN para cinzas e proteína (FDNcp) foi realizada nas amostras de alimentos e fezes para cálculo das digestibilidades de FDN e carboidratos não-fibrosos (CNF).

Os resultados de desempenho produtivo dos animais foram analisados em delineamento inteiramente casualizado, considerando o peso vivo uma co-variável, por meio de análises de regressão e de variância (SAS, 1995), a 10\% de significância.

Com o objetivo de avaliar os parâmetros nutricionais, conduziu-se outro experimento utilizando-se quatro novilhos mestiços não-castrados, com peso médio inicial de $300 \mathrm{~kg}$, fistulados no esôfago, rúmen e abomaso, conforme descrito por Leão et al. (1978).

A área experimental destinada aos novilhos fistulados foi composta de quatro piquetes de $B$. brizantha cv. Marandu com 0,4 ha, providos de bebedouros e comedouros cobertos.

O experimento foi conduzido em delineamento quadrado latino $4 \times 4$, com quatro tratamentos e quatro períodos experimentais de 14 dias, de modo que os sete primeiros dias de cada período foram destinados à adaptação dos animais aos tratamentos. Aos animais fistulados foram fornecidos diariamente, às $10 \mathrm{~h} 30$, os mesmos suplementos nas mesmas quantidades oferecidas aos animais utilizados para avaliação do desempenho.
Para avaliar a composição bromatológica da forragem consumida pelos animais, realizaram-se coletas de extrusa no segundo dia de cada período experimental, após jejum alimentar e hídrico de 16 horas. As coletas foram realizadas às $7 \mathrm{~h}$ utilizando-se bolsas coletoras com fundo telado, adaptadas em torno da fístula esofágica. Após 40 minutos de pastejo, as bolsas eram retiradas e as amostras pesadas, secas em estufa com ventilação forçada, a $65^{\circ} \mathrm{C}$ por 72 horas, trituradas em moinho tipo Willey com peneira de $1,0 \mathrm{~mm}$ e posteriormente submetidas às mesmas análises laboratoriais realizadas no experimento de desempenho.

A estimativa da produção de MS fecal e do fluxo de MS abomasal foi obtida infundindo diretamente no rúmen cartuchos de papel com 10 g de óxido crômico, acondicionados em dose única às $12 \mathrm{~h}$, a partir do terceiro dia do período experimental até o $13^{\circ}$ dia de cada período.

Realizaram-se seis coletas de fezes e seis de digesta abomasal de cada animal por período experimental: a primeira coleta foi realizada no oitavo dia do período, às $8 \mathrm{~h}$, e a cada 26 horas nos dias subseqüentes, até o $13^{0}$ dia, às $18 \mathrm{~h}$. As amostras foram pesadas e secas em estufa com ventilação forçada a $65^{\circ} \mathrm{C}$ e trituradas em moinho tipo Willey com peneira de 1,0 mm. Amostras compostas individuais por período foram feitas a partir do material préseco dos seis horários de coleta.

Das mesmas amostras de digesta abomasal foram retiradas alíquotas líquidas de $10 \mathrm{~mL}$ por coleta e feitas amostras compostas a cada animal $(60 \mathrm{~mL})$ dos seis horários de coleta. As amostras foram acondicionadas em potes plásticos com tampa e congeladas a $-20^{\circ} \mathrm{C}$ para posterior análise do teor de nitrogênio amoniacal.

No 14음 dia do período experimental, realizaram-se coletas de líquido ruminal, imediatamente antes (0 hora) e 4 horas após o fornecimento do suplemento. As amostras foram filtradas em camada tripla de gaze para determinação do pH e da concentração de amônia no líquido ruminal. As leituras de $\mathrm{pH}$ foram realizadas imediatamente após a coleta, com o auxílio de um peagâmetro digital. Para determinação da concentração de amônia ruminal, utilizou-se uma alíquota de $50 \mathrm{~mL}$ de líquido ruminal fixada em $1 \mathrm{~mL} \mathrm{de}_{2} \mathrm{SO}_{4} 1: 1$. As amostras foram congeladas a $-20^{\circ} \mathrm{C}$ para análises posteriores.

As concentrações de $\mathrm{N}-\mathrm{NH}_{3}$ nas amostras dos fluidos ruminal e abomasal foram determinadas mediante destilação com hidróxido de potássio $(\mathrm{KOH}) 2 \mathrm{~N}$, conforme técnica adaptada por Vieira (1980).

Para estimar a excreção de MS fecal, utilizou-se o indicador externo óxido crômico, segundo recomendações de Smith \& Reid (1955), considerando a razão entre a quantidade de indicador fornecido e sua concentração nas fezes: 
Quantidade fornecida do indicador (g)

Matéria seca
fecal (g/dia) $\quad \begin{gathered}\text { Concentração do indicador } \\ \text { nas fezes (\%) }\end{gathered}$

A FDA indigestível (FDAi) foi utilizada como indicador interno para estimativa do fluxo de MS abomasal, segundo metodologia descrita por Lippke et al. (1986). A concentração de FDAi nas amostras de suplemento, abomaso e extrusa foi obtida após incubação in situ por 144 horas. A relação entre a ingestão diária do indicador e sua concentração no abomaso foi determinada por meio da equação: $\mathrm{FMA}=[(\mathrm{EFxCIF}) / \mathrm{CIAB}] \times 100$; em que FMA = fluxo de MS abomasal (kg/dia); EF = excreção fecal (kg/dia); CIF = concentração do indicador nas fezes $(\mathrm{kg} / \mathrm{kg})$ e CIAB = concentração do indicador no abomaso (\%).

O consumo voluntário de MS foi estimado pela relação entre excreção fecal e a indigestibilidade, a partir do indicador interno FDAi, conforme descrito anteriormente, por meio da equação: CMS = $\{[(\mathrm{EF} \times \mathrm{CIF})-\mathrm{CIS}] / \mathrm{CIFOR}\}+$ CMSS, em que: CMS - consumo de MS (kg/dia); CIS = concentração de FDAi no suplemento (kg/dia); CIFOR = concentração de FDAi na forragem $(\mathrm{kg} / \mathrm{kg})$; e CMSS = consumo de MS de suplemento ( $\mathrm{kg} / \mathrm{dia})$.

Os carboidratos não-fibrosos (CNF) foram quantificados utilizando-se a seguinte equação: $\mathrm{CNF}=100$ $-(\% \mathrm{~PB}+\% \mathrm{FDNcp}+\% \mathrm{EE}+\%$ cinzas $)$; em que: FDNcp = FDN corrigida para cinzas e proteína.

A partir da composição bromatológica dos alimentos, foram obtidos os teores de NDT estimados $\left(\mathrm{NDT}_{\mathrm{EST}}\right)$, segundo equações sugeridas pelo NRC (2001), em que o fator 7 refere-se ao valor metabólico fecal:

$$
\mathrm{NDT}_{\text {EST }}=\mathrm{PBD}+2,25 \times \mathrm{AGD}+\mathrm{FDNpD}+\mathrm{CNFD}-7
$$

Para o cálculo do NDT observado (NDT ${ }_{\mathrm{OBS}}$ ), utilizou-se a equação:

$$
\mathrm{NDT}_{\mathrm{OBS}}=\mathrm{PBD}+2,25 \times \mathrm{EED}+\mathrm{FDNpD}+\mathrm{CNFD}
$$

Os teores de proteína degradável no rúmen (PDR) foram calculados conforme recomendações do NRC (2001), por meio da equação: $P D R=A+B *(k d / k d+k p)$, em que $A, B$, kd e kp significam, respectivamente, fração solúvel em água, fração insolúvel em água e potencialmente degradável, taxa de degradação da fração B e taxa de passagem da PB pelo rúmen.

\section{Resultados e Discussão}

A disponibilidade estimada de matéria seca total(DMST) média foi de $7.039 \mathrm{~kg} /$ ha (Tabela 2). Com o avanço da maturidade da planta e com o efeito da carga animal, houve redução na disponibilidade de forragem, associada à redu- ção acentuada na quantidade de folhas verdes (Tabela 2), ocasionando aumento de folhas secas e redução de colmos verdes, substituídos marcantemente por colmos secos.

Espécies forrageiras tropicais apresentam grande potencial de produção, entretanto, o acúmulo de MS ao longo do crescimento da planta é acompanhado de espessamento e aumento da lignificação da parede celular, além de redução expressiva na relação folha:colmo, o que compromete sua qualidade como alimento para ruminantes.

O teor médio de PB da extrusa foi 8,75\% na MS (Tabela 3), superior aos 7\% considerados por Minson (1990) como limite inferior para adequada atividade dos microrganismos ruminais, o que, segundo Mathis et al. (2002), poderia favorecer a digestibilidade das forragens altamente fibrosas.

Observou-se resposta positiva e linear no desempenho dos animais ao aumento nos níveis de energia no suplemento (Tabela 4), evidenciando que os animais responderam nesse período à suplementação energética. Esses dados confirmam

Tabela 2 - Disponibilidade de matéria seca total (DMST) e percentuais de folhas verdes (FV), folhas secas (FS), colmos verdes (CV), colmos secos (CS) e

\begin{tabular}{|c|c|c|c|c|}
\hline \multirow[t]{2}{*}{ Item } & \multicolumn{3}{|c|}{ Mês } & \multirow[t]{2}{*}{ Média } \\
\hline & Março/Abril & Abril/Maio & Maio/Junho & \\
\hline DMST (kg/ha) & 8.611 & 6.740 & 5.767 & 7.039 \\
\hline Folhas verdes (\%) & 31,00 & 6,43 & 5,52 & 14,32 \\
\hline Folhas secas (\%) & 14,15 & 27,35 & 31,96 & 24,49 \\
\hline Colmos verdes (\%) & 48,42 & 48,18 & 30,76 & 42,45 \\
\hline Colmos secos (\%) & 1,35 & 13,86 & 28,59 & 14,60 \\
\hline Matéria morta (\%) & 5,08 & 4,18 & 3,17 & 4,14 \\
\hline
\end{tabular}
matéria morta (MM) do pasto

Tabela 3 - Composição nutricional dos suplementos e da extrusa

\begin{tabular}{|c|c|c|c|c|c|}
\hline \multirow[t]{2}{*}{ Item } & \multicolumn{4}{|c|}{ Suplemento } & \multirow[t]{2}{*}{ Extrusa } \\
\hline & MM & GS1,0 & MGS1,5 & MGS2,0 & \\
\hline MS (\%) & 98,70 & 89,06 & 88,52 & 88,25 & 15,48 \\
\hline MO & - & 95,44 & 96,84 & 97,52 & 90,23 \\
\hline PB & - & 34,95 & 22,93 & 17,06 & 8,75 \\
\hline $\mathrm{PDR}^{1}$ & - & 66,24 & 61,43 & 59,08 & 70,19 \\
\hline $\mathrm{NIDN}^{2}$ & - & 28,77 & 21,59 & 18,09 & 50,48 \\
\hline $\mathrm{NIDA}^{2}$ & - & 8,96 & 6,30 & 5,00 & 20,48 \\
\hline $\mathrm{EE}$ & - & 17,29 & 11,68 & 8,95 & 2,10 \\
\hline Cinzas & - & 4,56 & 3,16 & 2,48 & 6,77 \\
\hline FDN & - & 25,99 & 24,84 & 24,28 & 71,86 \\
\hline FDNcp & - & 22,78 & 23,30 & 22,78 & 64,96 \\
\hline CNF & - & 20,42 & 38,93 & 48,73 & 17,42 \\
\hline FDA & - & 16,39 & 10,78 & 8,04 & 44,31 \\
\hline FDAi & - & 1,34 & 1,14 & 1,04 & 13,07 \\
\hline Lignina & - & 1,21 & 1,09 & 1,02 & 9,31 \\
\hline NDTest $^{3}$ & - & 93,42 & 87,61 & 84,76 & 49,62 \\
\hline
\end{tabular}
do B. brizantha cv. Marandu (\% MS)

${ }^{1}$ Estimado segundo Valadares Filho et al. (2002), \%PB; ${ }^{2} \% \mathrm{NT} ;{ }^{3} \mathrm{NRC}(2001)$. 
Tabela 4 - Peso vivo inicial (PVI), peso vivo final (PVF), ganho de peso total (GPT) e ganho médio diário (GMD) em novilhos a pasto sob suplementação energética

\begin{tabular}{|c|c|c|c|c|c|c|c|}
\hline \multirow[t]{2}{*}{ Item } & \multicolumn{4}{|c|}{ Suplemento } & \multirow[t]{2}{*}{ CV (\%) } & \multicolumn{2}{|c|}{ Efeito $^{1,2}$} \\
\hline & MM & GS1,0 & MGS1,5 & MGS2,0 & & $\mathrm{L}$ & $\mathrm{Q}$ \\
\hline Peso vivo inicial (kg) & 334 & 331 & 334 & 334 & & & \\
\hline Peso vivo final $(\mathrm{kg})^{3}$ & 390 & 398 & 407 & 403 & 3,1 & 0,0637 & ns \\
\hline Ganho de peso total (kg) & 56 & 67 & 73 & 69 & & & \\
\hline Ganho médio diário (g/dia) ${ }^{4}$ & 511 & 614 & 664 & 629 & 18,4 & 0,0637 & ns \\
\hline
\end{tabular}

${ }^{1} \mathrm{~L}$ e Q = efeitos de ordem linear e quadrática dos níveis de energia nos suplementos, respectivamente; ${ }^{2}$ ns = não-significativo a $10 \%$ de probabilidade pelo teste $\mathrm{F} ;{ }^{3} \hat{\mathrm{Y}}=391,34+7,4280 \mathrm{X}\left(\mathrm{r}^{2}=0,7714\right) ;{ }^{4} \hat{\mathrm{Y}}=0,5285+0,0675 \mathrm{X}\left(\mathrm{r}^{2}=0,7692\right)$.

informações de vários autores da literatura internacional, que verificaram melhorias no desempenho animal como resultado da suplementação energética, independentemente da fonte (Anderson al et., 1988; Grigsby et al., 1991; Vanzant \& Cochran, 1994).

Nas condições deste trabalho, as alterações no consumo de MS do pasto poderiam explicar a maior parte das oscilações no GMD, uma vez que os animais dependiam principalmente do pasto para o atendimento de suas necessidades energéticas, pois os suplementos atenderam menos de $25 \%$ desse requerimento e a proteína foi mantida em quantidades semelhantes para todos os tratamentos, exceto o controle. Contudo, o NRC (1996) indica que, com o aumento na quantidade de concentrado na dieta, a eficiência de uso da energia para mantença e ganho aumenta, visto que a energia do concentrado é mais eficientemente usada para mantença e ganho que a energia das forragens. Assim, reduções no consumo de forragem e mudanças marginais no consumo total de MO digestível poderiam ser compensadas parcialmente pela mudança na eficiência de uso da energia metabolizável. Também a suplementação energética pode alterar as exigências de energia de ruminantes em pastejo alterando o comportamento de pastejo ou influenciando a eficiência de uso dos nutrientes (Caton \& Dhuyvetter, 1996). Krysl \& Hess (1993), em revisão de dados, avaliaram a influência da suplementação sobre o tempo de pastejo e concluíram que, aumentando o nível de grão no suplemento, diminuiu-se o tempo em pastejo. Ressalta-se que acréscimos no ganho de peso dos animais à custa da substituição da forragem basal devem ser bem avaliados, pois resultam em um custo adicional que, dependendo do tipo de manejo e dos objetivos do sistema, pode não ser vantajoso.

Não houve efeito significativo da suplementação sobre o consumo de matéria seca total (MST), contudo, observou-se influência linear negativa sobre o consumo de forragem (MSP) (Tabela 5). Os dados foram semelhantes aos obtidos por Caton \& Dhuyvetter (1997), que, avaliando a suplementação com níveis crescentes de cevada em novilhos alimentados com feno de gramínea com $10 \%$ de PB, observaram redução no consumo de forragem sem alterações no consumo de MST.

Waldo (1986) afirmou que a suplementação de forragem com concentrado geralmente amplia o consumo total de MS, mas decresce o consumo de forragem. Segundo o NRC (1996), quando mais de $1,0 \mathrm{~kg}$ de suplemento é fornecido diariamente ao animal, a ingestão de forragem pode ser reduzida por substituição. A presença do efeito substitutivo parece ser mais marcante no uso de suplementos de natureza energética (Minson, 1990; Poppi \& McLennan, 1995) e maior em condições de melhor qualidade da forragem (Minson, 1990; Caton \& Dhuyvetter, 1997).

O consumo de MO do pasto também foi afetado negativa e linearmente pelo uso de suplementos. Esse resultado está acordo com dados descritos por Chase \& Hibberd (1987), que, ao fornecerem níveis crescentes de milho para vacas alimentadas com forragem de baixa qualidade, verificaram diminuições lineares no consumo de MO de forragem. Os resultados deste estudo condizem ainda com observações de Lusby \& Wagner (1986).

Carey et al. (1993) compararam polpa de beterraba, milho e cevada fornecidos diariamente a $1,3 \mathrm{~kg} /$ dia e concluíram que o consumo de forragem com $10 \%$ de PB foi afetado negativamente pelo uso de todos os três alimentos.

Nesta pesquisa, os consumos de FDN da dieta total e de FDN da pastagem também foram afetados linear e negativamente pelos níveis de suplemento, o que possivelmente está relacionado ao observado por Detmann et al. (2001), que fizeram referência a uma saturação na resposta funcional do consumo decorrente da alta disponibilidade de massa forrageira encontrada, o que, ao possibilitar alta seletividade, levaria à alta digestibilidade da MS ingerida. Assim, a adição à dieta de componentes de alto potencial de digestão pode ter rompido o limite de energia digestível limitante de consumo, invertendo o principal mecanismo regulatório, de físico para fisiológico, como descrito por Mertens (1992), o que justificaria o menor consumo de FDN pelos animais sob suplementação. 
Tabela 5 - Consumos de matéria seca total (MST) e de nutrientes do pasto (p)

\begin{tabular}{|c|c|c|c|c|c|c|c|}
\hline Item & \multicolumn{4}{|c|}{ Suplemento } & CV (\%) & \multicolumn{2}{|c|}{ Efeito $^{1,2}$} \\
\hline & \multicolumn{4}{|c|}{$\mathrm{kg} / \mathrm{dia}$} & & & \\
\hline MST & 5,30 & 5,33 & 5,63 & 4,87 & 6,9 & ns & ns \\
\hline $\mathrm{MSp}^{3}$ & 5,24 & 4,44 & 4,30 & 3,11 & 8,4 & $* *$ & ns \\
\hline MO & 4,76 & 4,89 & 5,19 & 4,55 & 6,2 & ns & ns \\
\hline $\mathrm{EE}$ & 0,11 & 0,25 & 0,25 & 0,23 & 3,1 & ns & ns \\
\hline $\mathrm{FDN}^{6}$ & 3,80 & 3,41 & 3,46 & 2,69 & 7,7 & $*$ & ns \\
\hline $\mathrm{FDNp}^{7}$ & 3,80 & 3,19 & 3,12 & 2,23 & 8,4 & $* *$ & ns \\
\hline $\mathrm{CNF}^{8}$ & 0,73 & 0,80 & 1,13 & 1,30 & 4,8 & $* *$ & ns \\
\hline $\mathrm{NDT}$ & 3,34 & 3,57 & 3,83 & 3,14 & 11,2 & ns & ns \\
\hline $\mathrm{MSp}^{9}$ & 19,23 & 15,92 & 15,10 & 11,73 & 11,0 & $*$ & ns \\
\hline MO & 17,29 & 17,82 & 18,94 & 16,77 & 5,7 & ns & ns \\
\hline $\mathrm{MOp}^{10}$ & 17,29 & 14,51 & 13,75 & 10,66 & 10,5 & $*$ & ns \\
\hline FDN $^{11}$ & 13,85 & 12,33 & 12,29 & 10,09 & 8,6 & $*$ & ns \\
\hline $\mathrm{FDNp}^{12}$ & 13,88 & 11,49 & 10,95 & 8,45 & 10,8 & $*$ & ns \\
\hline NDT & 12,00 & 12,98 & 13,89 & 11,64 & 9,5 & & \\
\hline
\end{tabular}

${ }^{1} \mathrm{~L}$ e $\mathrm{Q}=$ efeitos de ordem linear e quadrática dos níveis de energia nos suplementos, respectivamente.

$2 \mathrm{~ns},{ }^{*} \mathrm{e}^{* *}=$ não-significativo e significativo a 5 e $1 \%$ de probabilidade pelo teste $\mathrm{F}$, respectivamente.

${ }^{3} \hat{Y}=5,1184-0,7514 X\left(r^{2}=0,9197\right) ;{ }^{4} \hat{Y}=4,6259-0,6623 X\left(r^{2}=0,9226\right) ;{ }^{5} \hat{Y}=0,4441+0,3885 X-0,1542 X^{2}\left(R^{2}=0,9263\right) ;{ }^{6} \hat{Y}=3,7044-0,3202 X$ $\left(r^{2}=0,8256\right) ;{ }^{7} \hat{Y}=3,7085-0,5512 X\left(r^{2}=0,9113\right) ;{ }^{8} \hat{Y}=0,6257+0,3238 X\left(r^{2}=0,9509\right) ; 9 \hat{Y}=1,9087-0,3190 X\left(r^{2}=0,9554\right) ; 10 \hat{Y}=1,7257-0,2828 X$ $\left(r^{2}=0,9566\right) ;{ }^{11} \hat{Y}=1,3815-0,1488 X\left(r^{2}=0,8915\right) ;{ }^{12} \hat{Y}=1,3780-0,2293 X\left(r^{2}=0,9511\right)$.

O consumo de NDT não foi influenciado pelo nível de concentrado das dietas, portanto, a pastagem provavelmente proporcionou alta quantidade de nutrientes digestíveis, pois mesmo os níveis mais baixos de concentrado proporcionaram valores semelhantes aos níveis mais elevados, em média 3,47 kg/dia ou 12,63 g/kg de PV.

A relação entre a quantidade de MS da forragem que deixou de ser consumida e a quantidade de suplemento ingerido é denominada taxa de substituição (Reis et al., 1997). Neste trabalho, os coeficientes de substituição (CS) variaram de 0,31 a 0,42 (Tabela 5). Se a diminuição no consumo de forragem for igual à quantidade de concentrado consumida, o coeficiente de substituição será 1,0 e o suplemento terá pouco efeito na produção. Ao contrário, se o suplemento não tem efeito no consumo de forragem, o coeficiente de substituição é igual a zero e haverá benefício integral de seu uso, ao passo que, se esse coeficiente for negativo, haverá a caracterização de efeito aditivo do suplemento estimulando o consumo de forragem. Nos experimentos conduzidos por Paterson et al. (1994), foram constatados os "efeitos de substituição" com o fornecimento de alimentos energéticos.

Uma grande deficiência nas pesquisas conduzidas no Brasil sobre o uso de suplementação é a pouca atenção à quantificação do consumo de MS dos pastos onde são mantidos os animais. Normalmente, os resultados são avaliados somente quanto ao desempenho animal em resposta ao uso dos suplementos, no entanto, não se pode explicar com base exclusivamente nestes resultados se os melhores ou piores desempenhos são decorrentes do suplemento, "efeito de substituição", ou do aumento no consumo de forragem, "efeito aditivo".

Não foram encontradas diferenças significativas ( $\mathrm{P}>0,05)$ dos níveis de concentrado sobre as digestibilidades totais de MS, MO, EE, FDN, carboidratos totais (CT) e CNF (Tabela 6), que apresentaram médias de 59,17; 61,92; 54,09; 58,46; 62,89 e 87,27\%, respectivamente. Contudo, foi estimada digestibilidade aparente total máxima de $63,22 \%$ da PB com 0,832 kg de NDT na dieta.

A digestibilidade aparente ruminal da MO foi influenciada $(\mathrm{P}<0,05)$ pelos níveis de suplementação energética e seu valor máximo estimado foi de 75,87\% para o nível de $1,5 \mathrm{~kg}$ de suplemento. Estes resultados diferem dos reportados por Elizalde et al. (1999) de que a digestibilidade aparente ruminal da MO em novilhos não foi afetada pela inclusão de milho na dieta. Berchielli (1994) e Dutra et al. (1997) também não verificaram variação na digestibilidade aparente ruminal da MO decorrente do nível de concentra- 
Tabela 6 - Digestibilidades totais dos nutrientes das dietas

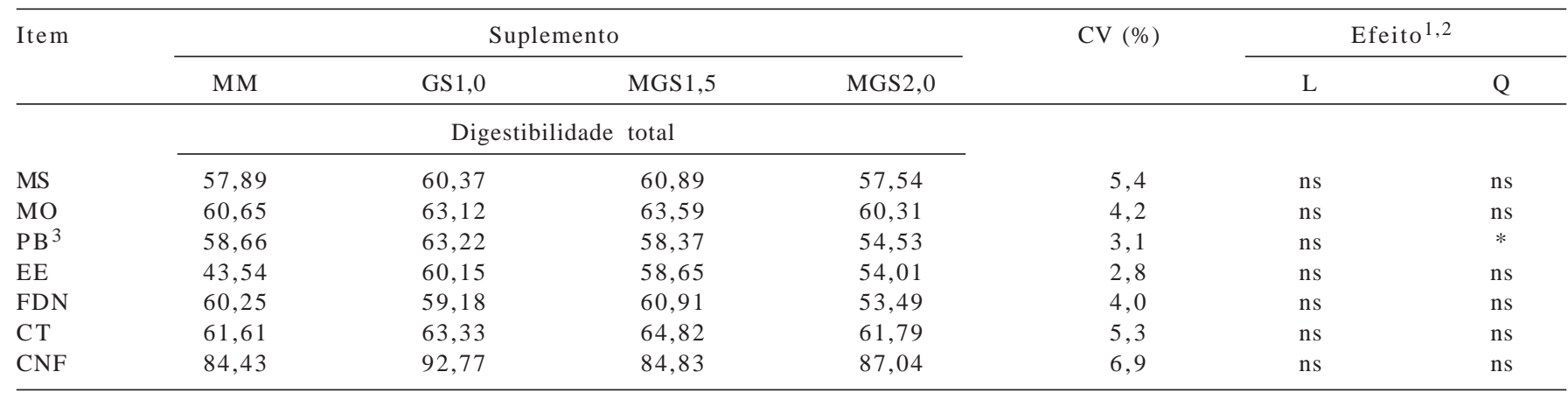

${ }^{1} \mathrm{~L}$ e $\mathrm{Q}=$ efeitos de ordem linear e quadrática dos níveis de energia nos suplementos, respectivamente.

$2 \mathrm{~ns} \mathrm{e}^{*}=$ não-significativo e significativo a $5 \%$ de probabilidade pelo teste $\mathrm{F}$, respectivamente.

${ }^{3} \hat{Y}=58,1634+9,9913 X-5,9082 X^{2}\left(R^{2}=0,8566\right)$.

Tabela 7 - Digestibilidades ruminais e intestinais dos nutrientes e valores estimados e observados de NDT das dietas

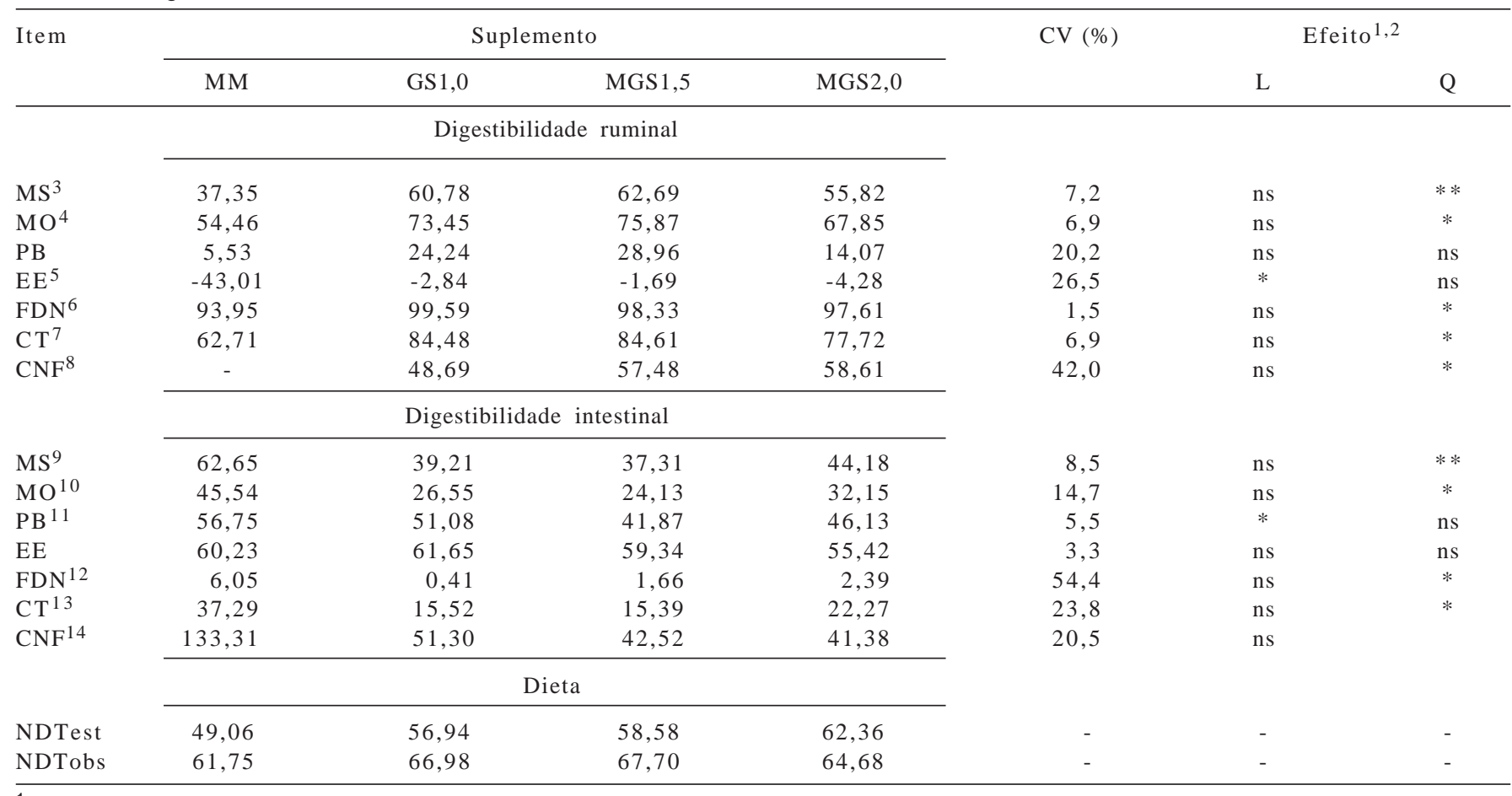

${ }^{1} \mathrm{~L}$ e $\mathrm{Q}=$ efeitos de ordem linear e quadrática dos níveis de energia nos suplementos, respectivamente.

$2 \mathrm{~ns},{ }^{*} \mathrm{e}{ }^{* *}=$ não-significativo e significativo a 5 e $1 \%$ de probabilidade pelo teste $\mathrm{F}$, respectivamente.

$3 \hat{Y}=36,0830+39,6910 X-14,6618 X^{2}\left(R^{2}=0,9797\right) ;{ }^{4} \hat{Y}=54,3345+33,7475 X-13,4591 X^{2}\left(R^{2}=0,9932\right) ;{ }^{5} \hat{Y}=-35,7640+20,2747 X\left(r^{2}=0,7449\right) ;{ }^{6}$ $\hat{Y}=93,6724+7,8196 X-2,8130 X^{2}\left(R^{2}=0,8434\right) ; 7 \hat{Y}=62,8000+37,3520 X-15,1385 X^{2}\left(R^{2}=0,9664\right) ; 8 \hat{Y}=-32,5742+122,7535 X-40,0842 X^{2}$ $\left(R^{2}=0,9635\right) ; 9 \hat{Y}=63,9170-39,6910 X+14,6618 X^{2}\left(R^{2}=0,9797\right) ; \quad \hat{Y}=1045,6655-33,7475 X+13,4591 X^{2}\left(R^{2}=0,9932\right) ; 11 \hat{Y}=55,0052-5,3743 X$ $\left(r^{2}=0,6833\right) ; 12 \hat{Y}=6,3276-7,8196 X+2,8130 X^{2}\left(R^{2}=0,8434\right) ; 13 \hat{Y}=37,2000-37,3520 X+15,1385 X^{2}\left(R^{2}=0,9664\right) ; 14 \hat{Y}=132,5742-122,7535 X$ $+40,0842 X^{2}\left(R^{2}=0,9635\right)$.

do da dieta, no entanto, Bürger et al. (2000) observaram decréscimo linear dos valores de digestibilidade ruminal deste nutriente com o aumento do nível de concentrado.

Valores de digestibilidade aparente ruminal do EE negativos ou próximos de zero seriam esperados, pois não há microrganismo ruminal capaz de utilizar lipídios como fonte energética, contudo, houve efeito linear positivo
( $\mathrm{P}<0,05)$ do nível de suplementação energética sobre a digestibilidade aparente ruminal desse nutriente. Ladeira et al. (1999) constataram efeito quadrático do nível de concentrado sobre a digestibilidade aparente ruminal do EE e sugeriram que os valores negativos para a digestibilidade desse nutriente podem ser conseqüências da síntese de lipídios microbianos. 
A digestibilidade ruminal da FDN apresentou valor máximo estimado de 99,59\%, correspondente ao nível de 1,0 kg de suplemento. Valores de digestibilidade da FDN próximos de $100 \%$ indicam que o fluxo de MS no abomaso foi subestimado provocando superestimativa das digestões ruminais. Poore et al. (1990), utilizando 90\% de concentrado, observaram redução linear na digestibilidade ruminal da FDN. Ladeira et al. (1999) também verificaram redução linear da digestibilidade ruminal de FDN e atribuíram esta redução à acidificação do pH ruminal com os níveis crescentes de concentrado na dieta.

Neste trabalho, foi encontrada resposta quadrática da digestibilidade aparente ruminal dos carboidratos totais (CT) aos níveis de concentrado na dieta. O valor máximo foi estimado em $85,82 \%$, possivelmente em decorrência da redução momentânea do $\mathrm{pH}$ ruminal (Tabela 8), atribuída ao maior aporte de CNF e ao desbalanço entre energia e proteína na dieta, causado principalmente pelo maior consumo de CNF e menor de PB (Tabela 5). Bürger et al. (2000), ao contrário, obtiveram média de $74,5 \%$ e Ladeira et al. (1999), 85,06\%, não verificando efeito de nível de concentrado sobre a DAR dos carboidratos totais.

Observou-se comportamento quadrático para as digestibilidades intestinais de MS, MO, FDN, CT e CNF, que apresentaram valores mínimos estimados de 37,09; 24,13; 0,41; 14,17 e 38,78\%, respectivamente. Contrariamente, Tibo et al. (2000), Bürger et al. (2000) e Berchielli (1994) não verificaram efeito do nível de concentrado sobre a digestibilidade aparente intestinal da MS. Adicionalmente, Ladeira et al. (1999) e Tibo et al. (2000) constataram efeitos lineares sobre a digestibilidade aparente intestinal da MO.

A digestibilidade aparente intestinal da PB foi afetada linear e negativamente pelos níveis de concentrado na dieta, possivelmente em virtude da pior qualidade da proteína do milho, principal ingrediente dos suplementos com maior conteúdo energético. Esses resultados diferem daqueles descritos por Ladeira et al. (1999) e Dias et al. (2000), que encontraram aumentos lineares sobre a digestibilidade aparente intestinal da PB com o aumento do nível de concentrado na dieta.

$\mathrm{O} \mathrm{pH}$ (0 e 4 horas) e as concentrações de $\mathrm{N}-\mathrm{NH}_{3}$ ruminal (0 e 4 horas) e $\mathrm{N}-\mathrm{NH}_{3}$ abomasal não foram influenciados de forma significativa pelos níveis de energia (Tabela 8) e apresentaram valores médios, respectivamente, de 6,26; 6,09; 13,11; 15,49 e 8,54 mg/dL. Contudo, embora sem diferença estatística, no tratamento com maior nível de suplementação energética (2 kg), o pH ruminal atingiu o valor mínimo de 5,86 4 horas após o fornecimento do concentrado, valor inferior ao de 6,2, apontado por $\varnothing$ rskov (1982) e Mould et al. (1983) como limite mínimo para manutenção das atividades normais das bactérias celulolíticas e digestão de palhas. Esses pesquisadores indicaram que a redução no $\mathrm{pH}$ ruminal poderia ser responsável pela redução na digestibilidade da fibra associada à suplementação com grãos. Church (1988) observou que ruminantes alimentados com dietas à base de volumoso mantiveram o $\mathrm{pH}$ ruminal entre 6,2 e 6,8 ; enquanto, naqueles consumindo concentrado, o $\mathrm{pH}$ variou de 5,8 a 6,6 .

A concentração média de amônia ruminal antes (13,11 mg/dL) e 4 horas após $(15,49 \mathrm{mg} / \mathrm{dL}$ de líquido ruminal) o fornecimento dos suplementos não foi influenciada pelos níveis de suplementação acima dos 5,0 mg/100 mL de líquido ruminal, considerados por Satter \& Roffler (1979) mínimo para que a fermentação e a atividade microbiana não sejam limitadas. Também foram superiores

Tabela 8 - pH e concentrações de amônia ruminal ( $\mathrm{mg} / \mathrm{dL}$ de líquido ruminal) e abomasal ( $\mathrm{mg} / \mathrm{dL}$ de líquido abomasal) em novilhos a pasto sob suplementação energética

\begin{tabular}{|c|c|c|c|c|c|c|c|}
\hline \multirow[t]{3}{*}{ Horário } & \multicolumn{4}{|c|}{ Suplemento } & \multirow[t]{2}{*}{ CV (\%) } & \multicolumn{2}{|c|}{ Efeito $^{1,2}$} \\
\hline & $\mathrm{MM}$ & GS1,0 & MGS1,5 & MGS2,0 & & $\mathrm{L}$ & Q \\
\hline & \multicolumn{4}{|c|}{$\mathrm{pH}$ ruminal } & & & \\
\hline $0^{3}$ & 6,00 & 6,39 & 6,26 & 6,39 & 4,2 & ns & ns \\
\hline \multirow[t]{2}{*}{$4^{4}$} & 6,12 & 6,23 & 6,15 & 5,86 & 4,2 & ns & ns \\
\hline & \multicolumn{4}{|c|}{ Amônia ruminal } & & & \\
\hline $0^{3}$ & 12,77 & 14,76 & 11,14 & 13,80 & 29,0 & ns & ns \\
\hline \multirow[t]{3}{*}{$4^{4}$} & 11,01 & 17,59 & 16,96 & 16,42 & 29,0 & ns & ns \\
\hline & \multicolumn{4}{|c|}{ Amônia abomasal } & & & \\
\hline & 7,45 & 9,23 & 9,23 & 8,27 & 50,0 & ns & ns \\
\hline
\end{tabular}

\footnotetext{
$1 \mathrm{~L}$ e $\mathrm{Q}=$ efeitos de ordem linear e quadrática dos níveis de energia nos suplementos, respectivamente.

2 ns = não-significativo a $5 \%$ de probabilidade pelo teste $\mathrm{F}$.

3 Medida realizada imediatamente antes do fornecimento do suplemento.

${ }^{4}$ Medida realizada 4 horas após o fornecimento do suplemento.
} 
ao valor citado por Van Soest (1994) para máximo crescimento microbiano (10 mg/100 mL de líquido ruminal).

Em pesquisa com novilhos em pastagem suplementada com energia ou proteína, Elizalde et al. (1998) verificaram que a concentração de $\mathrm{N}$ amoniacal tendeu a ser maior nos animais sem suplementação, de 21,9 e 19,2 mg/100 mL, respectivamente, fato não confirmado neste estudo; pelo contrário, houve inversão desse conceito, pois as concentrações de amônia ruminal nos animais sob suplementação $(15,11 \mathrm{mg} / 100 \mathrm{~mL})$ foram sempre numericamente superiores às dos animais sem suplementação (médias de $11,89 \mathrm{mg} / 100 \mathrm{~mL}$ ).

Não foram encontradas diferenças na concentração de $\mathrm{N}-\mathrm{NH}_{3}$ na digesta abomasal. Segundo Acedo (2004), esse efeito pode ter sido ocasionado pela utilização desse nitrogênio pela microbiota ruminal, além da absorção do excesso de $\mathrm{N}$ pela parede do rúmen, impedindo que houvesse grandes diferenças na quantidade de $\mathrm{N}-\mathrm{NH}_{3}$ que passou ao abomaso.

\section{Conclusões}

Ganhos adicionais de 20 a 30\% em bovinos em pastejo podem ser obtidos com o fornecimento de suplementos com quantidades crescentes de energia durante o período de transição águas-seca.

\section{Literatura Citada}

ACEDO, T.S. Suplementos múltiplos para bovinos em terminação, durante a época seca, e em recria, nos períodos de transição seca-águas e águas. Viçosa, MG: Universidade Federal de Viçosa, 2004. 58p. Dissertação (Mestrado em Zootecnia) - Universidade Federal de Viçosa, 2004.

ANDERSON, S.J.; MERRILL, J.K.; KLOPFENSTEIN, T.J. Soybean hulls as an energy supplement for the grazing ruminant. Journal of Animal Science, v.66, p.2959, 1988.

BERCHIELLI, T.T. Efeito da relação volumoso:concentrado sobre a partição da digestão, a síntese de proteína microbiana, produção de ácidos graxos voláteis e o desempenho de novilhos em confinamento. Belo Horizonte: Universidade Federal de Minas Gerais, 1994. 104p. Tese (Doutorado em Zootecnia) - Universidade Federal de Minas Gerais, 1994.

BÜRGER, P.J.; PEREIRA, J.C.; COELhO DA SILVA, J.F. et al. Consumo e digestibilidade aparente total e parcial em bezerros holandeses alimentados com dietas contendo diferentes níveis de concentrado. Revista Brasileira de Zootecnia, v.29, n.1, p.206-214, 2000.

CAREY, D.A.; CATON, J.S.; BIONDINI, M. Influence of energy source on forage intake, digestibility, in situ forage degradation, and ruminal fermentation in beef steers fed medium quality brome hay. Journal of Animal Science, v.71, p.2260, 1993.

CATON, J.S.; DHUYVETTER, D.V. Manipulation of maintenance requirements with supplementation. In: GRAZING LIVESTOCK NUTRITION CONFERENCE, 3., 1996. Proceedings... Western Section, American Society of Animal Science, 1996. v.47, n.1, p.72.
CATON, J.S.; DHUYVETTER, D.V. Influence of energy supplementation on grazing ruminants: requirements and responses. Journal of Animal Science, v.75, p.533-542, 1997.

CHASE JR., C.; HIBBERD, C.A. Utilization of low-quality native grass hay by beef cows fed increasing quantities of corn grain. Journal of Animal Science, v.65, n.2, p.557-566, 1987.

$\mathrm{CHURCH}$, D.C. Salivary function and production. In: $\mathrm{CHURCH}$, D.C. (Ed.) The ruminant animal: digestive physiology and nutrition. New Jersey: Prentice Hall, 1988. p.172-201.

DETMANN, E.; PAULINO, M.F.; ZERVOUDAKIS, J.T. et al. Suplementação de novilhos mestiços durante a época das águas: parâmetros ingestivos e digestivos. Revista Brasileira de Zootecnia, v.30, n.4, p.1340-1349, 2001.

DIAS, H.L.C.; VALADARES FILHO, S.C.; COELHO DA SILVA, J.F. et al. Consumo e digestões totais e parciais em novilhos F1 Limousin x Nelore alimentados com dietas contendo cinco níveis de concentrado. Revista Brasileira de Zootecnia, v.29, n.2, p.545-554, 2000.

DUTRA, A.R.; QUEIROZ, A.C.; PEREIRA, J.C. et al. Efeito dos níveis de fibra e das fontes de proteínas sobre o consumo e digestão dos nutrientes em novilhos. Revista Brasileira de Zootecnia, v.26, n.4, p.787-796, 1997.

ELIZALDE, J.C.; CREMIN, J.D.J.; FAULKNER, D.B. et al. Performance and digestion by steers grazing tall fescue and supplemented with energy and protein. Journal of Animal Science, v.76, p.1691-1701, 1998.

ELIZALDE, J.C.; MERCHEN, N.R.; FAULKNER, D.B. Supplemental cracked corn for steers fed fresh alfalfa: I. Effects on digestion of organic matter, fiber and starch. Journal of Animal Science, v.77, p.457-466, 1999.

GOMIDE, J.A. A técnica de fermentação ruminal in vitro na avaliação de forragens. Revista Brasileira de Zootecnia, v.3, n.2, p.210-24, 1974.

GRIGSBY, K.N.; ROUQUETTE, F.M.; ELLIS, W.C. et al. Use of self-limiting fishmeal and corn supplements for calves grazing rye-ryegrass pastures. Journal Production Agriculture, v.4, p.476, 1991.

KÖSTER, H.H.; COCHRAN, R.C.; TITGEMEYER, E.C. et al. Effect of increasing degradable intake protein on intake and digestion of low-quality, tall grass prairie forage by beef cows. Journal of Animal Science, v.74, p.2478-2481, 1996.

KRYSL, L.J.; HESS, B.W. Influence of supplementation on behavior of grazing cattle. Journal of Animal Science, v.71, p.2546, 1993.

LADEIRA, M.M.; VALADARES FILHO, S.C.; COELHO DA SILVA, J.F. et al. Consumo e digestibilidades aparentes totais e parciais de dietas contendo diferentes níveis de concentrado, em novilhos Nelore. Revista Brasileira de Zootecnia, v.28, n.2, p.395-403, 1999.

LEÃO, M.I.; COELHO DA SILVA, J.F.; CARNEIRO, L.H.D.M. Implantação de fístula ruminal e cânula duodenal reentrante em carneiros, para estudos de digestão. Ceres, v.25, n.1, p.42-54, 1978.

LIPPKE, H.; ELLIS, W.C.; JACOBS, B.F. Recovery of indigestible fiber from feces of sheep and cattle on forage diets. Journal of Dairy Science, v.69, n.2, p.403-412, 1986.

LUSBY, K.S.; WAGNER, D.G. Effects of supplements on feed intake. In: OWENS, F.N. (Ed.) Feed intake by beef cattle. Stillwater: Oklaloma Agricultural Experimental Station MP121, 1986. p.173.

MATHIS, C.P.; COCHRAN, R.C.; HELDT, J.S. et al. Effects of supplemental degradable intake protein on utilization of medium-to low-quality forages. Journal of Animal Science, v.78, n.1, p.224-232, 2002.

MEHREZ, A.Z.; ØRSKOV, E.R.; McDONALD, I. Rates of rumen fermentation in relation to ammonia concentration. British Journal of Nutrition, v.38, n.3, p.437-443, 1977.

MERTENS, D.R. Análise da fibra e sua utilização na avaliação e formulação de rações. In: SIMPÓSIO INTERNACIONAL DE 
RUMINANTES, REUNIÃO ANUAL DA SOCIEDADE BRASILEIRA DE ZOOTECNIA, 29., 1992, Lavras. Anais... Lavras: Sociedade Brasileira de Zootecnia, 1992. p.188.

MERTENS, D.R. Regulation of forage intake. In: NATIONAL CONFERENCE ON FORAGE QUALITY. EVALUATION AND UTILIZATION, 1994, Lincoln. Proceedings... Lincoln: University of Nebraska, 1994. p.450-493.

MINSON, D.J. Forage in ruminant nutrition. New York: Academic Press, 1990. 483p.

MOULD. F.L.; ØRSKOV, E.R.; MANN, S.O. Associative effects of mixed feeds. 2. The effect of dietary additions of bicarbonate salts on the voluntary intake and digestibility of diets containing various proportions of hay and barley. Animal Feed Science Technology, v.10, n.15, p.25, 1983.

NOLLER, C.H.; NASCIMENTO JR., D.; QUEIROZ, D.S. Exigências nutricionais de animais em pastejo. In: SIMPÓSIO SOBRE MANEJO DE PASTAGEM, 13., 1996, Piracicaba. Anais... Piracicaba: Fundação de Estudos Agrários Luiz de Queiroz, 1997. p.319-352.

NATIONAL RESEARCH COUNCIL - NRC. Nutrient requirements of beef cattle. 7.ed. Washington, D.C.: National Academy Press, 1996. 242p.

NATIONAL RESEARCH COUNCIL - NRC. Nutrient requirements of dairy cattle. 7.ed. Washington, D.C.: National Academy Press, 2001. 381p.

ORSKOV, E.R. Protein nutrition in ruminants. New York: Cambridge Academic Press, 1982. 162p.

PATERSON, J.A.; BELYEA, R.L.; BOWMAN, J.B. et al. The impact of forage quality and supplementation regimen on ruminant animal intake and performance. In: FAHEY JR., G.C. (Ed.). Forage quality, evaluation, and utilization. Madison: ASA, CSSA, SSSA, 1994. p.59-114.

PAULINO, M.F.; RUAS, J.R.M. Considerações sobre a recria de bovinos de corte. Informe Agropecuário, v.13, n.153/154, p.68-80, 1988.

PELL, A.N.; SCHOFIELD, P. Computerized monitoring of gas production to measure forage digestion in vitro. Journal of Dairy Science, v.76, p.1063-1073, 1993.

POORE, M.H.; MOORE, J.A.; SWINGLE, R.S. Differential passage rates and digestion of neutral detergent fiber from grain and forages in 30,60 e 90\% concentrate diets fed to steers. Journal of Animal Science, v.68, p.2965-2973, 1990.
POPPI, D.K.; McLENNAN, S.R. Protein and energy utilization by ruminants at pasture. Journal of Animal Science, v.73, p.278290, 1995.

REIS, R.A.; RODRIGUES, L.R.A.; PEREIRA, J.R.A. A suplementação como estratégia de manejo da pastagem. In: SIMPÓSIO SOBRE MANEJO DE PASTAGEM, 13., 1997, Piracicaba. Anais... Piracicaba: Fundação de Estudos Agrários Luiz de Queiroz, 1997. p.123-150.

SATTER, L.D.; ROFFLER, R.E. Nitrogen requirement and utilization in dairy cattle. Journal of Dairy Science, v.58, n.8, p.1212-1237, 1979.

SILVA, D.J.; QUEIROZ, A.C. Análise de alimentos: métodos químicos e biológicos. 3.ed. Viçosa, MG: Editora UFV, 2002. 165p.

SMITH, A.M.; REID, J.T. Use of chromic oxide as an indicator of fecal output for the purpose of determining the intake of a pasture herbage by grazing cows. Journal of Dairy Science, v.38, n.5, p.515-524, 1955.

STATISTICAL ANALYSES SYSTEM - SAS. SAS/STAT: user's guide. 11.ed. Cary: SAS Institute, 1995.

TIBO, G.C.; VALADARES FILHO, S.C.; VALADARES, R.F.D. et al. Níveis de concentrado em dietas de novilhos mestiços F1 Simental x Nelore. 1. Consumo e digestibilidades. Revista Brasileira de Zootecnia, v.29, n.3, p.910-920, 2000.

VALADARES FILHO, S.C.; ROCHA JR., V.R.; CAPPELLE, E.R. Tabelas brasileiras de composição de alimentos para novinos. CQBAL 2.0. Viçosa, MG: Suprema Gráfica Ltda, 2002. 297p.

Van SOEST, P.J. Nutritional ecology of the ruminant. 2.ed. Ithaca: Cornell University Press, 1994. 476p.

Van SOEST, P.J.; ROBERTSON, J.B.; LEWIS, B.A. Methods for dietary fiber, neutral detergent fiber, and nonstarch polyssacarides in relation to animal nutrition. Journal of Animal Science, v.74, n.10, p.3583-3597, 1991.

VANZANT, E.S.; COCHRAN, R.C. Performance and forage utilization by beef cattle receiving increasing amounts of alfalfa hay as a supplement to low-quality, tallgrass-prairie forage. Journal of Animal Science, v.72, p.1059, 1994.

VIEIRA, P.F. Efeito do formaldeído na proteção de proteínas e lipídios em rações para ruminantes. Viçosa MG: Universidade Federal de Viçosa, 1980. 98p. Tese (Doutorado em Zootecnia) Universidade Federal de Viçosa, 1980.

WALDO, D.R. Effect of forage quality on intake and forageconcentrate interactions. Journal of Dairy Science, v.69, n.2, p.617-631, 1986. 